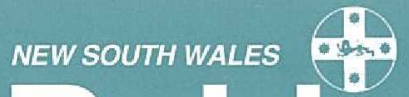 Public Health Bulletin
}

\section{INVESTIGATION OF POSSIBLE PATIENT-TO-PATIENT TRANSMISSION OF HEPATITIS C IN A HOSPITAL}

K Chant, Medical Officer of Health, SWSAHS; K Kociuba, Area Infectious Diseases Physician, SWAPS; A/Prof. R Munro, Director of Microbiology, SWAPS; S Crone, Public Health Nurse, SWSAHS; R Kerridge, Deputy Director Anaesthetics, SWSAHS; $J$ Quin, Director Sexual Health Clinic, SWSAHS; $M$ Wyland, Theatre Nurse Educator, SWSAHS; G Miller, Infection Control Consultant, SWSAHS; I Turner, Gastroenterologist; J Brown, Public Health Nurse, SWSAHS; L Baird, Trainee Environmental Health Officer, SWSAHS; A / Prof. S. Locarnini, Director VIDRL, Fairfield Hospital, Melbourne; S. Bowden, Head of Molecular Microbiology VIDRL, Fairfield Hospital, Melbourne; K G Kenrick, Principal Scientist and Head, Department of Virology / Biochemistry, NSW Blood Bank; C Maidment, Senior Scientist in Charge, Serology Department, SWAPS.

(1) n December 1993 the NSW Health Department was notified that two patients had presented with acute hepatitis $\mathrm{C}$ five and seven weeks after undergoing minor surgical procedures in the same operating session at a Sydney private hospital early that year. Neither case had other risk factors for acute hepatitis $\mathrm{C}$. This article summarises progress to date in epidemiologic and laboratory investigations to determine how these cases (subsequently known as Case B and Case $\mathrm{C}$ ) became infected. The investigations were carried out by the South Western Sydney Area Health Service (SWSAHS) and the Department's Public Health Division, with the consent and co-operation of the patients and the staff involved in their care.

\section{EPIDEMIOLOGIC INVESTIGATION}

Initially this comprised the following steps:

- confirmation of the diagnoses of acute hepatitis $\mathrm{C}$;

- review of the patients' risk factors and medical history, including a search for stored blood or evidence of any previous testing for antibodies to hepatitis $\mathrm{C}$ virus (anti-HCV), in an attempt to pinpoint possible times of exposure;

- anti-HCV testing of hospital staff involved in the surgery session;

- anti-HCV testing of patients who had procedures in the same hospital's operating rooms on the same day as Cases B and C, the following day and the preceding day; and

- a review of infection control policies and practices at the hospital.

The diagnosis of acute hepatitis $\mathrm{C}$ in both Cases $\mathrm{B}$ and $\mathrm{C}$ was based on clinical symptoms (jaundice, lethargy, nausea and vomiting), abnormal liver function tests consistent with acute viral hepatitis, and the exclusion of other common causes of viral hepatitis. Case B was found to be anti-HCV positive 10 weeks after the surgical procedure, having been negative at the onset of the illness three weeks beforehand. Case $\mathrm{C}$ was anti-HCV positive on initial presentation seven weeks post-surgery.

Thirteen patients underwent surgical procedures in the same operating session as Cases B and C (the index session). The other 11 people were tested for anti-HCV, and three were found to be anti-HCV positive.

They were designated Cases A, D and E.

\section{Correspondence}

Please address all correspondence and potential contributions to:

\section{The Editor,}

NSW Public Health Bulletin, Public Health Division, NSW Health Department Locked Bag No 961, Nortb Sydney NSW 2059 Telepbone: (O2) 3919191 Facsimile: (02) 3919029 


\section{Hepatitis C investigation}

\section{Continued from page 47}

Anti-HCV testing was offered to 51 patients who were treated in other operating sessions on the same day as the index session, or on the day before or the day after. To date, 47 people have been tested for anti-HCV, and one person was found to be anti-HCV positive (designated Case $\mathrm{F}$ ). Case $\mathrm{F}$ had a procedure on the afternoon before the index session.

Cases A, D, E and F were interviewed in relation to risk factors for hepatitis $\mathrm{C}$ and previous hepatitis $\mathrm{C}$ testing history. Relevant medical and occupational records were reviewed to identify possible risk factors.

None of the five cases who had procedures in the index session had had prior testing for anti-HCV, and no stored specimens from before the index session were available for testing on any of the cases.

\section{LABORATORY INVESTIGATIONS}

Serological testing was performed by the South Western Area Pathology Service (SWAPS) and local private pathology services. All anti-HCV positive patients were tested or retested by SWAPS using a second generation enzyme linked immunosorbent assay (ELISA) $)^{a}$. Samples found to be positive using this assay were reassayed by the NSW Blood Bank ${ }^{\mathrm{b}}$.

Anti-HCV positive sera were tested for the presence of hepatitis B surface antigen, hepatitis B core antibody and hepatitis B surface antibody ${ }^{c}$.

Hepatitis $\mathrm{C}$ virus (HCV) RNA detection by reverse transcriptase polymerase chain reaction (PCR) assays was used to detect hepatitis $\mathrm{C}$ virus in aspectically collected blood samples from Cases B, C, D, E and F and on stored serum from Cases $\mathrm{A}$ and $\mathrm{C}$. These tests were carried out by the Victorian Infectious Diseases Reference Laboratory (VIDRL) ${ }^{\mathrm{d}}$, Fairfield Hospital, Melbourne. All PCR results were confirmed by the VIDRLe.

Genotyping of HCV RNA positive cases was also performed by the VIDRL ${ }^{f}$. Further comparison of the HCV RNA sequences is in progress.

\section{FINDINGS}

\section{The theatre list for the index session}

The order of the five cases who had surgery during the index session is shown in Table 1 where the results of reverse transcriptase(RT) $\mathrm{PCR}$ to detect $\mathrm{HCV}$ viraemia are also recorded.

\section{a Sanofi Diagnostics Pasteur, France.}

b Murex Diagnostics and Abbott Diagnostics, and further

characterised using an immunoblot assay (Innogenetics, Belgium). c Roche Diagnostic Systems.

$\mathrm{d}$ This assay used nested primers from the untranslated region ( $5^{\prime}$ UTR) with two sequential rounds of amplification for greater sensitivity.

e The confirmatory test was Roche Diagnostics Systems HCV RNA detection test.

fGenotyping was done using a reverse phase hybridisation assay developed by Innogenetics that allows simple and rapid determination of HCV genotypes after PCR amplification ${ }^{1}$.

\begin{tabular}{|c|c|c|c|}
\hline \multicolumn{4}{|c|}{ TABLE 1} \\
\hline \multicolumn{4}{|c|}{$\begin{array}{l}\text { THEATRE LIST POSITIONS OF THE FIVE CASES } \\
\text { WHO HAD SURGERY IN THE INDEX SESSION }\end{array}$} \\
\hline Cases & $\begin{array}{l}\text { Position on } \\
\text { theatre list }\end{array}$ & $\begin{array}{l}\text { HCV RT PCR } \\
\text { Early } 1993\end{array}$ & $\begin{array}{l}\text { HCV RT PCR } \\
\text { Early } 1994\end{array}$ \\
\hline A & 5 & not done & positive \\
\hline B & 6 & not done & positive \\
\hline C & 8 & positive & negative \\
\hline D & 9 & not done & positive \\
\hline$E$ & 10 & not done & positive \\
\hline
\end{tabular}

\section{Results of tests to detect hepatitis $\mathrm{C}$ virus in the} cases (Table 1)

Case $\mathrm{F}$, whose operation was on the previous day to the index session, was also HCV RT PCR positive.

\section{Description of the cases}

Case F

- $\quad$ Female in her 30s.

- Clinical history suggests that she acquired chronic hepatitis C before 1993.

Case A

- Male in his 40s.

- History of hepatitis B about 20 years ago. A review of his medical records revealed he had risk factors for hepatitis $\mathrm{C}$.

- Serologic testing indicated past exposure to hepatitis A and hepatitis B.

Case B

- Female in her 20s.

- No history of having received blood or blood products, injecting drug use, tattooing, electrolysis or occupational exposures to blood or body fluids.

- She had only one sexual partner over five years, and he tested anti-HCV negative early in 1994.

Case C

\begin{tabular}{l|l} 
- & Female in her 60 s. \\
No history of having received blood or blood
\end{tabular} products since 1969 (she had normal immunoglobulin in 1965, a blood transfusion in 1965, and anti-D following delivery of her children). No history of injecting drug use, tattooing, electrolysis or occupational exposures to blood/body fluids.

- She has had one lifetime sexual partner who tested anti-HCV negative in 1994 and all current household contacts tested anti-HCV negative.

Case D

- Female in her 20s.

- No history of having received blood or blood products, injecting drug use, tattooing or electrolysis. She was employed as an assistant at two nursing homes for several years. Her duties involved assisting residents with their activities 
of daily living. No documentation of needlestick injuries in the staff incident book or employment records maintained by the nursing homes. She has had one lifetime sexual partner who tested anti-HCV negative early in 1994.

Case E

- Male in his 30s.

No history of having received blood or blood products, injecting drug use, tattooing or occupational exposures to blood or body fluids. He has had one sexual partner over 12 years, and she tested anti-HCV negative early in 1994. The procedure in the index session was his first invasive procedure.

Results of anti-HCV tests on surgical personnel and hospital staff

The surgeon, anaesthetist, surgical assistant, theatre and recovery nurses and the orderly associated with the index session were anti-HCV negative after the index session.

\section{The hospital's infection control policies and practices \\ Review process}

Policies and practices were reviewed by a team comprising a microbiologist, infectious disease clinicians, an infection control nurse, a theatre nurse educator, anaesthetist and Public Health Unit staff. In addition structured interviews on infection control were administered to relevant medical and theatre nursing staff and the infection control nurse of the hospital. The review focused on ward areas, operating rooms, the central sterile supply unit (CSSU) and the recovery area.

\section{Pre-operative procedures}

The cases were hospitalised in different ward areas. Premedications were given in different areas and at different times, and multi-dose vials were not used.

\section{Surgical instrument sterilisation and usage}

All cases had surgical procedures performed in the same operating room. Case A's procedure involved a steroid injection into a joint. Cases B, C, D and E had a variety of procedures. Because the nature of their procedures was different, it was extremely unlikely that any particular instrument(s) could have been used on all cases.

It was reported that all surgical instruments were washed manually, then autoclaved, either in a "flash" autoclave in the operating suite, or in a jacketed downward displacement autoclave in the CSSU. All autoclaves were reportedly checked weekly with spore tests, and daily with chemical indicators. There was a written service report indicating that a routine service was done on the autoclaves on the afternoon following the index session, and the contractor stated that they were all operational before and after the service.

The team was advised that a drill, which was used on Case F, would have been used on Case $\mathrm{C}$ and probably also on Case B, but not the other cases. This drill was also used on the person immediately following Case $\mathrm{F}$, and this person tested anti-HCV negative. A saw used on Case $\mathrm{F}$ could have been used on Case B, but this saw was also used on the person immediately following Case $\mathrm{F}$ and on the first patient on the index session, both of whom tested anti-HCV negative.

Assuming the reported procedures were followed, the saw and drill would have been flash autoclaved when required for consecutive patients in a session and both instruments would have been through a jacketed autoclave cycle in CSSU the evening before the index session.

\section{Anaesthetic procedures}

All five cases had general anaesthesia, Laryngeal masks (LMs) were used on Cases A, B, C, D and E. It was reported that a packed sterile LM was used for each person. Size 3 LMs were used for females, and size 4 for males, so it would have been impossible for a single LM to be used on all cases. The reported practice of the anaesthetist was to insert the LM without a laryngoscope, after spraying the deflated LM cuff with a lignocaine $10 \%$ solution. He reported that he did not spray lignocaine directly into the patient's oropharynx.

He further reported that it was his practice to draw up intravenous anaesthetic agents in separate syringes if the injectate from one ampoule was to be used on two or more patients. Fentanyl and propofol were administered to all five cases. The drug register for fentanyl shows that none of the five cases shared a common fentanyl ampoule. Purchase records showed that propofol was bought only in $200 \mathrm{mg}$ ampoules at the time of the index session. The dose of propofol given to the cases ranged from $120 \mathrm{mg}$ to $220 \mathrm{mg}$. Therefore, even if an ampoule was shared, it is extremely unlikely that it would have been used for more than three patients. The anaesthetist reported that he used an 18- or 19-gauge needle for drawing up the propofol in a $20 \mathrm{ml}$ syringe, and discarded the needle and syringe after drawing up or administering the dose for each patient.

Sucker heads and/or suction catheters were reportedly changed after each patient. Separate suction equipment was used in operating rooms and in the recovery area. Some patients, such as Cases A and C, were unlikely to have required suction in the recovery area because they were recorded as having been conscious on arrival. Others were unlikely to have required suction in the operating room because their LMs were recorded as having been still in situ when they arrived in the recovery area.

Anaesthetic circuits, consisting of inspiratory and expiratory tubing with a "Y"-piece at the "patient end", were reportedly changed at the end of every operating session. The anaesthetist stated that neither bacterial nor viral filters were used in the anaesthetic circuit. 


\section{Hepatitis C investigation}

Continued from page 49

\section{Genotyping results}

Genotyping showed that Case F was infected with HCV genotype $3 \mathrm{a}$ and that Cases $\mathrm{A}, \mathrm{B}, \mathrm{C}, \mathrm{D}$ and $\mathrm{E}$ were infected with $\mathrm{HCV}$ genotype $1 \mathrm{a}$.

\section{COMMENTARY}

Hepatitis $\mathrm{C}$ is a recently discovered RNA virus and is the most common cause of non-A, non-B hepatitis. It is transmitted primarily by blood-to-blood contact, although viral RNA has been detected in other body fluids such as saliva, ascites fluid and semen ${ }^{2,3}$. Transmission of hepatitis $\mathrm{C}$ by blood products, by needle or equipment sharing during injecting drug use, and through occupational injury by "sharps" contaminated with infected blood ${ }^{4}$, have been well documented. Sexual transmission of hepatitis $\mathrm{C}$ and vertical transmission from mother to baby occurs ${ }^{5,6}$, but less frequently than for hepatitis B or HIV. Transmission of hepatitis C within households (possibly by sharing shaving equipment) ${ }^{7}$ has been reported. In addition the potential for saliva to transmit hepatitis $\mathrm{C}$ has been postulated ${ }^{2,8}$. Acute hepatitis $\mathrm{C}$ is usually anicteric, and it was the coincidence of two clinically jaundiced patients among the four which drew attention to the incident.

Apart from possible nosocomial transmission of hepatitis $\mathrm{C}$ involving renal patients in dialysis units ${ }^{9 \mathrm{a}, 9 \mathrm{~b}}$, no other instance of patient-to-patient transmission of hepatitis $\mathrm{C}$ has been reported to our knowledge.

In this investigation healthcare worker-to-patient transmission was excluded. However patient-to-patient transmission remains the most plausible explanation for the cluster. Two potential source patients were identified: Case $\mathrm{A}$, who underwent a procedure prior to Cases B, C, D and E in the index session; and Case F, who underwent a procedure in the afternoon before the index session. At the time of writing, one person who had a procedure on the day before the index session remains to be tested. Apart from haemostats, the instruments reportedly used on this patient were common only to Case D.

The review of the pattern of surgical instrument usage and sterilisation procedures indicated that Case F could not have been the source, a conclusion supported by the viral genotyping. This left Case A as the most likely source because:
- in the operating list, Case A preceded Cases B, C, D and E.
- his risk factor history suggested exposure to hepatitis $\mathrm{C}$ virus before the index day (probably in the 1970 s or 1980 s); and
- genotyping demonstrated that Cases A, B, C, $\mathrm{D}$ and $\mathrm{E}$ had the same genotypes (type $1 \mathrm{a}$ ).

The possibility of the cluster being due to chance was explored. By chance alone, the probability that the four out of five sequential patients, who followed case A and who had no identifiable risk factor for infection, were anti-HCV positive was estimated to be $2.5 \times 10^{-10}$ (assuming that the prevalence of hepatitis $\mathrm{C}$ was $0.4 \%$ in a population without risk factors for hepatitis $\mathrm{C}$ infection - a typical prevalence for NSW blood donors). ${ }^{10}$

Thus the cluster is most unlikely to have been due to chance. This is corroborated by the facts that two of the cases (Cases B and C) developed acute hepatitis C 5-7 weeks after the index session, no risk factors were identified to explain these cases' illnesses, and no hepatitis $\mathrm{C}$ risk factors were identified for Cases $\mathrm{D}$ and $\mathrm{E}$.

While no clear mechanism of transmission of hepatitis $\mathrm{C}$ virus from Case $\mathrm{A}$ to Cases $\mathrm{B}, \mathrm{C}, \mathrm{D}$ and $\mathrm{E}$ was identified, the available evidence suggests that patient-to-patient transmission occurred during the surgical session early in 1993. The genotyping results give further support to this conclusion, but there have been only limited studies of HCV types in Australia and it appears that type 1 is commonly found ${ }^{11}$. Direct sequencing of HCV RNA from Cases A, B, C, D and E is in progress and may provide better evidence of the degree of the relatedness of the HCV strains.

The results of the investigation suggest that transmission did not occur via surgical instruments, multidose vials, reuse of laryngeal masks, laryngoscopes or suction equipment.

Below are two possible mechanisms which could account for transmission to Cases B, C, D and E. The second hypothesis is the more plausible of the two.

The first hypothesis involves inadvertent contamination and reuse of a needle or syringe used to draw up the intravenous anaesthetic agents propofol or fentanyl. Given that the propofol ampoules contain only $200 \mathrm{mg}$ each, inadvertent contamination of an ampoule might account for transmission to Case B but could not account for transmission to Cases C, D and E, unless there was contamination of the drawing-up needle or syringe and subsequent reuse. The anaesthetist and anaesthetic nurse assistants report that a sterile needle and syringe is used to draw up each dose, as is the routine practice.

The second hypothesis involves contamination of anaesthetic circuitry. Case A may have coughed at some stage during the procedure, introducing respiratory secretions into a reusable part of the anaesthetic circuitry (e.g. the "patient end" of the "Y"-piece). This would then have acted as a reservoir for the virus, which could have been transmitted to other patients as droplets via minor breaks in their oropharyngeal mucosa. By providing a clear airway, the laryngeal mask may have facilitated transmission. Significantly, the seventh patient on the theatre list, who has remained anti-HCV negative, had a short anaesthetic without the use of a LM. Both the duration of anaesthesia and airway management technique may have prevented transmission of the virus. 
LMs commonly cause minor trauma to the pharyngeal mucosa, evidenced by bloodstained secretions on the laryngeal mask on removal. In a review of 25 cases in 1994 who had LMs inserted, 5 out of 25 (20\%) had macroscopic evidence of blood on the LM. ${ }^{12}$

Transmission via bloodstained respiratory secretions is more plausible than transmission via saliva or nonbloodstained respiratory secretions, because salivary transmission of hepatitis $\mathrm{C}$ has not been documented. However, HCV RNA has been detected in saliva ${ }^{2,3}$, experimental transmission of hepatitis $\mathrm{C}$ by saliva to a chimpanzee has been described ${ }^{8}$, and transmission of hepatitis $\mathrm{C}$ by a human bite has been reported ${ }^{13}$.

\section{CONCLUSION}

This investigation has drawn attention to possible patient-to-patient transmission of hepatitis $\mathrm{C}$ in a private hospital.

1. Sturyver L, Rossau R, Wyseur A et al. Typing of hepatitis C virus isolates and characterization of new subtypes using a line probe assay. $J$ of general virology 1993; 74:1093-1102.

2. Wang JT, Wang TH, Sheu JC et al. Hepatitis C virus RNA in saliva of patients with posttransfusion hepatitis and low efficiency of transmission among spouses. $J$ of medical virology 1992; 36:28-31. 3. Chang TC, Liou KC, Young XZ et al. Detection of hepatitis C virus RNA in saliva, urine, seminal fluid and ascites. Abstract.

International symposium on viral hepatitis and liver disease. Tokyo 1993.

4. Kiyosawa K, Sodeyama T, Tanaka E et al. Hepatitis C in hospital employees with needlestick injuries. Ann Inter Med 1991; 115:367-9. 5. Ohto H, Terazawa S, Sasaki N et al. Transmission of hepatitis C virus from mothers to infants. N Engl J Med 1994; 330:744-50. 6. Akahane Y, Aikawa T, Sugai Y et al. Transmission of HCV between spouses. Lancet 1992; 339:1059-60.

7. Gordon SC, Patel AH, Kulesza GW et al. Lack of evidence for the heterosexual transmission of hepatitis C. Am J of gastroenterology 1992; 87:1849-51.

8. Abe K, Inchauspe G. Transmission of hepatitis C by saliva. Lancet $1991 ; 337: 248$.

9a. Huang CS, Ho MS, Vang CS et al. Hepatitis C markers in hemodialysis patients. $J$ of Clinical Microbiology 1993; 31:1764-9. 9b. Medlin C, Allander T, Roll M et al. Seroconversion to hepatitis C virus in dialysis patients: a retrospective and prospective study. Nephron. 1993; 65:40-5.

10. Personal communication, Fung SC. Public Health Division, NSW Health Department, 1994.

11. McOmish F, Yap PL, Dow BC et al. Geographical distribution of hepatitis $\mathrm{C}$ virus genotypes in blood donors: an international collaborative survey. J of Clinical Microbiology 1994; 32:884-892.

12. Personal communication, Kerridge R, 1994.

13. Dusheiko GM, Smith M, Scheuer PJ. Hepatitis transmitted by human bite. Lancet 1990; 336:503-04.

\section{ACKNOWLEDGMENTS}

We acknowledge the contribution of Dr Chris Liddle. We would like to extend thanks to the Cases A, B, C, $\mathrm{D}, \mathrm{E}$ and $\mathrm{F}$, their general practitioners and specialists, the staff of the hospital, serology staff of SWAPS (Ms Helen Anderson, Dr Peter Newton, Dr Iain Gosbell), Mr Buzz Cutts, Area Sexual Health Clinic, and the other patients and general practitioners contacted in the course of the investigation for their assistance. We also thank Professor Yvonne Cossart, Dr Greg Knoblanche and Dr Geoff McCaughan; staff of NSW Health Department's Public Health Division (Dr Michael Levy, Ms Wendy Manning, Mr David Lowe, Dr George Rubin, Dr Sue Morey and Dr Greg Stewart). Finally, thank you to staff at the Public Health Unit, in particular Ms Sumi Nair and Dr Mitchell Smith, and Dr Michael Frommer, NSW Health Department.

\section{EDITORIAL COMMENT}

The report by Chant et al of possible patient-to-patient transmission of hepatitis $\mathrm{C}$ in a private hospital operating session comes soon after the report of possible patient-to-patient transmission of HIV. The latter event has triggered a re-evaluation of infection control procedures, and widespread changes have already occurred in clinical practices for the disinfection and sterilisation of reusable equipment. The hepatitis $\mathrm{C}$ investigation underlines the importance of the reviews of infection control policies and practices which are currently in progress nationally and in NSW. Available evidence has led to a hypothesis that hepatitis $\mathrm{C}$ virus was transmitted through contamination of anaesthetic circuitry. The NSW Infection Control Policy for HIV, AIDS and associated conditions, published in 1992, states that "A filter for the anaesthetic circuit must be used to prevent cross-infection of the anaesthetic circuit." This precaution was primarily intended to prevent transmission of airborne pathogens such as Mycobacterium tuberculosis. Reportedly, filters were not used in the operating session in which hepatitis $\mathrm{C}$ transmission is hypothesised to have occurred, and it appears that they were not in general use at this time. As part of its review of infection control procedures, the NSW Health Department is assessing compliance with the Infection Control Policy, and associated implementation and enforcement issues.

\section{PUBLIC HEALTH EDITORIAL STAFF 1995}

The editor of the Public Health Bulletin is Dr Michael Frommer, Director, Research and Development, NSW Health Department. Dr Lynne Madden is production manager.

The Bulletin aims to provide its readers with population health data and information to motivate effective public health action. Articles, news and comments should be 1,000 words or less in length and include a summary of the key points to be made in the first paragraph. References should be set out using the Vancouver style, the full text of which can be found in British Medical Journal 1988; 296:401-5.

Please submit items in hard copy and on diskette, preferably using WordPerfect, to the editor, NSW Public Health Bulletin, Locked Mail Bag 961, North Sydney 2059. Facsimile (02) 3919029.

Please contact your local Public Health Unit to obtain copies of the NSW Public Health Bulletin. 